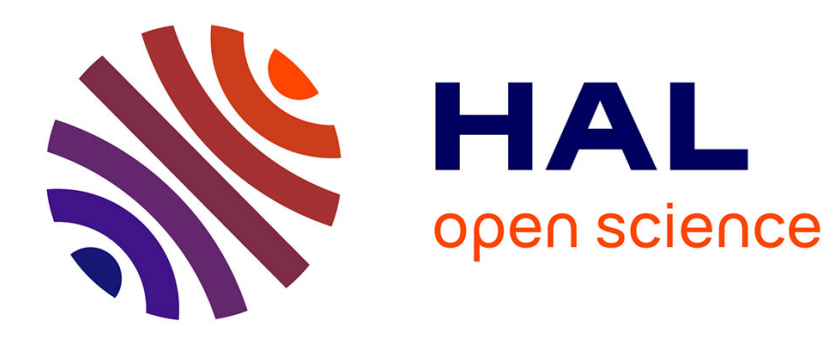

\title{
On APFIM of Grain Boundaries in a Nickel Base Superalloy
}

\author{
M. Thuvander, K. Stiller
}

\section{To cite this version:}

M. Thuvander, K. Stiller. On APFIM of Grain Boundaries in a Nickel Base Superalloy. Journal de Physique IV Proceedings, 1996, 06 (C5), pp.C5-247-C5-252. 10.1051/jp4:1996540 . jpa-00254419

\section{HAL Id: jpa-00254419 https://hal.science/jpa-00254419}

Submitted on 1 Jan 1996

HAL is a multi-disciplinary open access archive for the deposit and dissemination of scientific research documents, whether they are published or not. The documents may come from teaching and research institutions in France or abroad, or from public or private research centers.
L'archive ouverte pluridisciplinaire HAL, est destinée au dépôt et à la diffusion de documents scientifiques de niveau recherche, publiés ou non, émanant des établissements d'enseignement et de recherche français ou étrangers, des laboratoires publics ou privés. 


\title{
On APFIM of Grain Boundaries in a Nickel Base Superalloy
}

\author{
M. Thuvander and K. Stiller \\ Department of Physics, Chalmers University of Technology, 41296 Göteborg, Sweden
}

\begin{abstract}
Experimental details of atom probe field ion microscopy (APFIM) of a Ni-16Cr-9Fe alloy are presented. In particular, studies concerning analysis of intergranular carbides and borides and segregation to grain boundaries are described. It was found that $\mathrm{Ni}_{23} \mathrm{~B}_{6}$ precipitates are very sensitive to preferential field evaporation, which necessitates optimization of the analysis conditions. In the FIM images, nickel- and boron-rich precipitates exhibited either dark or bright contrast with respect to the austenitic matrix. Analysis of a grain boundary that contained a high level of segregated carbon, revealed that carbon is partially field evaporated as complex ions. In this analysis, chromium and carbon often appeared next to each other in the ion chain. Together, these two observations indicate nucleation of chromium carbides, which are known to form after extended heat treatment at the applied temperature $\left(600^{\circ} \mathrm{C}\right)$.
\end{abstract}

\section{INTRODUCTION}

The grain boundary microstructure of the investigated material is of importance because similar alloys have been found to be susceptible to intergranular stress corrosion cracking (IGSCC) under certain conditions [1]. IGSCC occurs in many austenitic materials, such as stainless steels and superalloys [2]. This phenomenon has been of particular interest in the nuclear power industry, since failures of pipes in steam generators have caused costly repairs. A common material that is used in this application is the nickel based Alloy 600 , with major composition $\mathrm{Ni}-16 \mathrm{Cr}-9 \mathrm{Fe}$ (wt\%). Alloy 600 contains carbon, $0.01-0.1$ wt\%, which has a major influence on the microstructure. Because of its low solubility in the material [3], carbon segregates to grain boundaries during heat treatment and subsequently forms precipitates, mainly chromium carbides. In materials alloyed with boron, precipitation of nickel borides has also been observed $[4,5]$, resulting in a complex grain boundary microstructure.

To obtain detailed information about the grain boundary microstructure of Alloy 600, an experimental technique with high spatial resolution together with the possibility of making quantitative chemical analysis of all elements including carbon and boron is needed. APFIM fulfils these requirements [5-8]. In this paper we report details concerning specimen preparation, contrast of intergranular precipitates in FIM images and field evaporation effects observed when analysing model materials with compositions similar to commercial Alloy 600 .

\section{EXPERIMENTAL}

\subsection{Equipment}

An energy compensated atom probe was used for microanalysis. The instrument has been previously described in detail [9-11]. The analysis temperature was varied in the range $40-90 \mathrm{~K}$. Neon, at a pressure of $30 \mathrm{mPa}$, was used as the imaging gas, whereas chemical analysis was performed at about $30 \mathrm{nPa}$. Voltage pulse fractions of $15 \%, 20 \%$ and $25 \%$ were used at a pulse frequency of $167 \mathrm{~Hz}$ and a pulse duration about $5 \mathrm{~ns}$. The standing voltage was controlled to obtain a constant evaporation rate of about 10 ions per minute and per square nanometer. The detection system has eight timing channels, which limits the number of ions that can be detected per pulse. Before analysis, the specimens were investigated in a Philips 300 transmission electron microscope (TEM), operating at $100 \mathrm{kV}$. 


\subsection{Materials}

The compositions of the investigated materials are presented in table 1 . They are model materials of a higher purity than commercial Alloy 600 . Depending on the solution annealing treatment, the grain size varied from $20 \mu \mathrm{m}$ (Alloy A) to $200 \mu \mathrm{m}$ (Alloy B).

Table 1. Composition of the investigated materials (at.\%).

\begin{tabular}{ccccccccc}
\hline Alloy & $\mathrm{Ni}$ & $\mathrm{Cr}$ & $\mathrm{Fe}$ & $\mathrm{C}$ & $\mathrm{B}$ & $\mathrm{Si}$ & $\mathrm{Al}$ \\
\hline $\mathrm{A}$ & 71.6 & 17.6 & 10.3 & 0.10 & $<0.005$ & 0.16 & 0.11 \\
$\mathrm{~B}$ & 73.0 & 17.6 & 9.2 & 0.14 & 0.04 & - & - \\
\hline
\end{tabular}

\subsection{Specimen preparation}

A standard preparation technique was applied to fabricate sharp needle shaped specimens. In the first step a neck was created by electropolishing in a layer of $10 \%$ perchloric acid and $20 \%$ glycerol in methanol. The layer was floating on tricloroethylene. In the second step, the whole blank was electropolished in $2 \%$ perchloric acid in 2-butoxyethanol until the blank fractured at the position of the neck created in the first step. The circuit was automatically broken after the fracture. The voltage that was used for both steps was approximately $22 \mathrm{~V}$. The success rate of the method was about $90 \%$.

To enable grain boundary studies of a material with a grain size much larger than the accessible depth of atom probe analysis, which is typically $100 \mathrm{~nm}$, special preparation techniques are necessary. Electropolishing, using short voltage pulses, in the same electrolyte as in step two above was used to produce specimens containing a grain boundary close to the tip apex $[12,13]$. Pulsed polishing (backpolishing) and subsequent TEM inspection were repeatedly performed to monitor the specimen preparation process. Specimens containing a grain boundary several micrometers away from the tip apex could be successfully back-polished only if the specimen shape was suitable. In order to maintain a small tip radius and a symmetrical cross section, the taper angle should be less than $30^{\circ}$. On the other hand, specimens with extremely low taper angles are also unwanted, because in that case the amount of material that is removed per pulse is hard to predict.

A pulse of $10 \mathrm{~ms}$ at a voltage of $22 \mathrm{~V}$ typically shortened the tip by about $200 \mathrm{~nm}$ and a pulse of $2 \mathrm{~ms}$ by about $50 \mathrm{~nm}$ (taper angle approximately $20^{\circ}$ ). To remove smaller amounts of material, polishing was performed at $15 \mathrm{~V}$ for $1 \mathrm{~ms}$, which removed less than $10 \mathrm{~nm}$. When the grain size was $200 \mu \mathrm{m}$, not more than one grain boundary was accessible per specimen, so if too much material was removed that specimen could not be used further. For the preparation of specimens containing a grain boundary close to the tip apex, the success rate for Alloy A was about $50 \%$, whereas it was only about $10 \%$ for Alloy B, due to the large grain size. The most distant grain boundary that was successfully analysed was originally 30 $\mu \mathrm{m}$ away from the tip apex. A problem with back-polishing is that the specimen tends to get an elliptical cross section after extensive polishing, due to variations in polishing rate with crystallographic orientation.

\section{RESULTS AND DISCUSSION}

\subsection{Field evaporation of $\mathrm{Ni}_{23} \mathrm{~B}_{6}$}

It has previously been shown by TEM that $\mathrm{Ni}_{23} \mathrm{~B}_{6}$ is one of two main types of intergranular precipitates, the other is $\mathrm{Cr}_{7} \mathrm{C}_{3}$, in materials similar to Alloy $\mathrm{B}$ in this investigation [4]. When analysing $\mathrm{Ni}_{23} \mathrm{~B}_{6}$ by atom probe: at a specimen temperature of $80 \mathrm{~K}$ using a pulse fraction of $20 \%$, a standard condition that gave reliable results for matrix analysis, the obtained boron concentration was higher than expected. TEM analysis, using electron diffraction, showed undoubtedly that the precipitate was $\mathrm{Ni}_{23} \mathrm{~B}_{6}$ (fcc structure with lattice parameter $1.06 \mathrm{~nm}$ ), i.e. with an expected boron concentration of 20.7 at.\%. Therefore, the composition was measured at various temperatures and using different voltage pulse fractions. From the relatively large precipitate in figure 1 , about 1.000 ions were detected for a number of different experimental conditions. The results are presented in figure 2 . It is obvious that the obtained boron concentration was strongly dependent on the specimen temperature and in particular on the pulse fraction. The high values of the boron concentration that were obtained at low pulse fractions and high temperatures must have been a consequence of preferential field evaporation [14] of nickel. Boron has a high evaporation field [14] and has often been shown to image brightly, e.g. in $\mathrm{NiAl}$ [15] and $\mathrm{Ni}_{4} \mathrm{Mo}$ [16], and therefore it is expected that its content will be too high if preferential evaporation occurs [17]. 
It is also interesting to note that no complex ions were detected, contrary to what has been observed in analysis of boron-containing $\mathrm{Ni} 4 \mathrm{Mo}$, where nickel and boron formed compound ions, such as $\mathrm{NiB}$ and $\mathrm{NiB}_{2}$ [16]. The result is not particularly surprising, because the chemical bonding between nickel and boron should be different in the two phases.

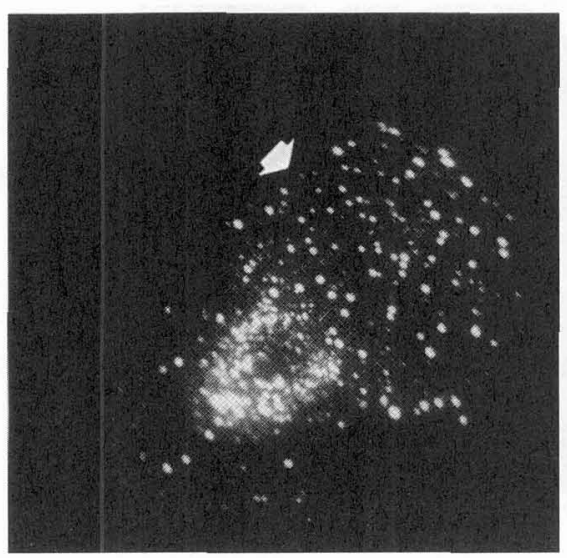

a)

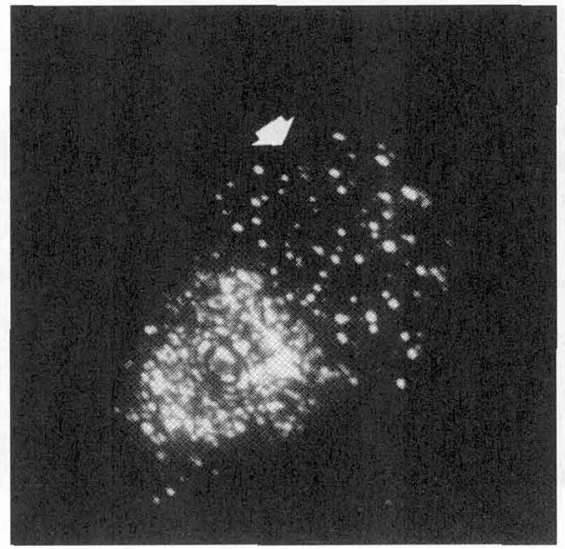

b)

Figure 1: Field ion images of a darkly appearing intergranular $\mathrm{Ni}_{23} \mathrm{~B}_{6}$ precipitate (arrowed) in Alloy $\mathrm{B}$, obtained using neon as imaging gas. Before imaging the specimen was field evaporated using a pulse fraction of $15 \%$ and $25 \%$ in a) and b), respectively. The large, bright spots in the precipitate region most probably originated from boron atoms. The material was heat treated at $700^{\circ} \mathrm{C}$ for $10 \mathrm{~h}$.

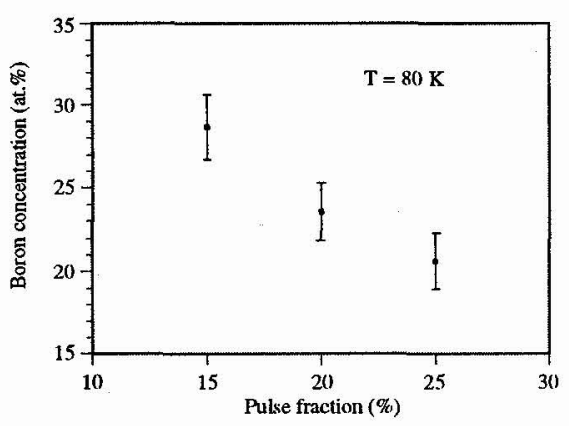

a)

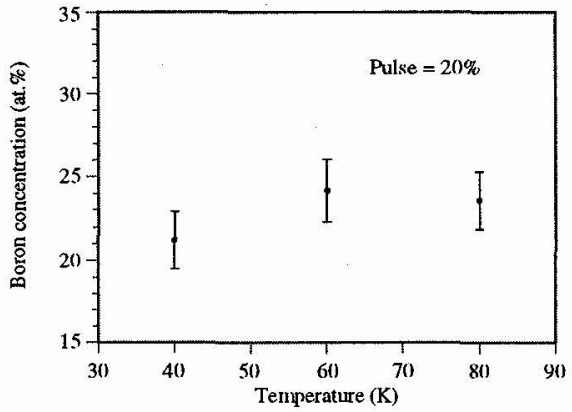

b)

Figure 2: Variation of boron concentration in $\mathrm{Ni}_{23} \mathrm{~B}_{6}$ with the experimental conditions. Correct composition at $80 \mathrm{~K}$ is obtained for a pulse fraction of $25 \%$. At $40 \mathrm{~K}$ the optimum pulse fraction is $20 \%$.

\subsection{Field ion microscopy of precipitates}

Three types of intergranular precipitates have been previously observed by FIM in this material [5]: $\mathrm{Cr}_{7} \mathrm{C}_{3}$, $\mathrm{Ni}_{23} \mathrm{~B}_{6}$ and a chromium boride, probably of type $\mathrm{Cr}_{7} \mathrm{~B}_{3}$ [4]. The latter phase was observed only occasionally. In the field ion image, $\mathrm{Cr}_{7} \mathrm{C}_{3}$ appeared dark with respect to the matrix and $\mathrm{Cr}_{7} \mathrm{~B}_{3}$ bright. Previously, the authors have reported that $\mathrm{Ni}_{23} \mathrm{~B}_{6}$ gives bright contrast [5]. However, recent analyses have shown that precipitates rich in nickel and boron can exhibit bright or dark contrast with respect to the matrix. Bright contrast was observed in two different specimens when small $(10 \mathrm{~nm})$ precipitates were situated between two grains, figure 3 , whereas dark contrast was observed in the images of three large $(100 \mathrm{~nm})$ precipitates. An example is presented in figure 1. In these cases one of the grains had been 
electropolished away leaving the precipitate in contact with only one grain. The reason for the difference in contrast is at present not well understood but some possible explanations are discussed below.

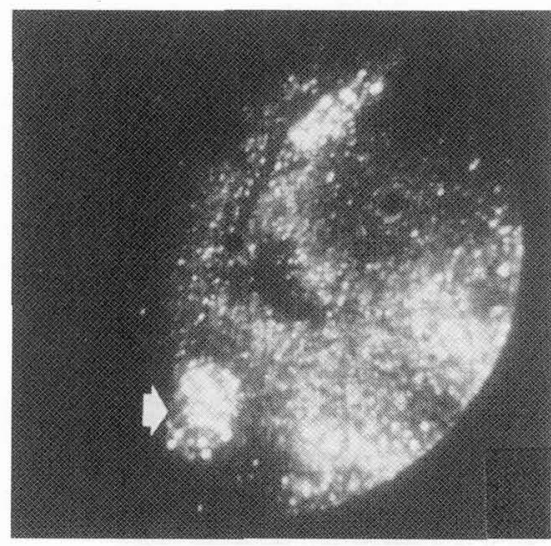

a)

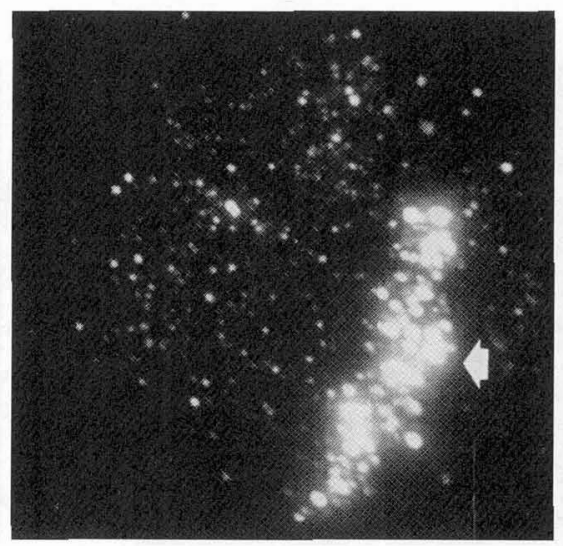

b)

Figure 3: Field ion images of two grain boundaries containing brightly appearing precipitates (arrowed) in Alloy B, obtained using neon as imaging gas. Before imaging the specimens were field evaporated using pulse fractions of $15 \%$ and $20 \%$ in a) and b), respectively. The precipitate in a) was a nickel boride. The intergranular precipitation in b) was a mixture of chromium boride and nickel boride. Both materials were heat treated at $700^{\circ} \mathrm{C}$ for $1 \mathrm{~h}$.

The bright spots appearing in the image of the dark precipitate originate from boron atoms that, as mentioned above, have a high evaporation field and therefore are retained on the surface. The fact that principally only boron atoms are imaged, explains why the density of spots is low in the dark regions of figure 1. The contrast in FIM images may change depending on the experimental conditions used during atom probe analysis [17]. When the applied conditions lead to strong preferential evaporation the density of retained atoms will be higher resulting in a brighter image. The image of a brightly appearing precipitate in figure $3 \mathrm{a}$ ) was recorded at $90 \mathrm{~K}$ at a voltage equal to the $\mathrm{DC}$ voltage reached after atom probe analysis using a pulse fraction of $15 \%$. According to the diagrams in figure 2 , this condition results in preferential evaporation and hence gives rise to a brighter image compared to what is obtained when the conditions are optimized. However, the darkly appearing precipitate remained dark with respect to the matrix independently of the used pulse fraction, see figure 1 . This indicates that the marked difference in contrast between the precipitates in figure 1 and figure 3 was not due to preferential evaporation effects.

The contrast of FIM images depends also on temperature and DC voltage [14]. The observed contrast of the precipitate in figure 1 did not appreciably change when the specimen temperature was varied between $60 \mathrm{~K}$ and $80 \mathrm{~K}$. The dark contrast, with respect to the matrix, also remained when the DC voltage was increased from a low value, giving rise to practically no contrast, to a voltage where DC evaporation occurred for both matrix and precipitate. Therefore, it is concluded that the difference in contrast between dark and bright precipitates can not simply be explained by differences in experimental conditions.

One possible explanation for the different contrast of the precipitates would be a difference in their chemistry. However, the compositions of bright and dark precipitates obtained using similar experimental conditions are not significantly different (see table 3 ) and close to this expected for $\mathrm{Ni}_{23} \mathrm{~B}_{6}$. This is the only type of nickel-rich precipitate observed in the material in our TEM/EDX investigations of extraction replicas and also according to the investigation by Kruger and Was of a similar material [4]. The observed boron concentration is also close to this of $\mathrm{Ni}_{3} \mathrm{~B}$, which is a stable phase in the binary nickel-boron system [18]. However, this phase has never been observed in the investigated type of material. The only other boride discovered in similar nickel base alloys is $\mathrm{M}_{3} \mathrm{~B}_{2}$ [19], which has a much higher boron content than these obtained in our study. Analysis of electron diffraction from large, darkly appearing precipitates confirmed that they have the same structure as $\mathrm{Ni}_{23} \mathrm{~B}_{6}$. On the other hand, the structure of the brightly appearing precipitates could not be undoubtedly determined from electron diffraction, hecause of their small size. It might then be possible that these small precipitates are precursors of larger $\mathrm{Ni}_{23} \mathrm{~B}_{6}$ with a similar composition but with a different structure. If this is true, the observed difference in contrast of the 
precipitates could be explained by the presence of two different nickel boride phases. To confirm this statement a more detailed TEM investigation using a high performance microscope should be conducted.

Table 2. Composition (in at.\%) of nickel borides in Alloy B.

\begin{tabular}{ccccc}
\hline & Figure 1a & Figure 1b & Figure 3a & Figure 3b \\
\hline $\mathrm{B}$ & $28.7 \pm 2.0$ & $20.6 \pm 1.7$ & $26.6 \pm 1.7$ & $20.4 \pm 0.8$ \\
$\mathrm{C}$ & $0.1 \pm 0.1$ & $0.2 \pm 0.2$ & $0.2 \pm 0.2$ & $1.2 \pm 0.2$ \\
$\mathrm{Ni}$ & $61.8 \pm 1.8$ & $68.1 \pm 1.7$ & $64.2 \pm 1.6$ & $66.4 \pm 1.4$ \\
$\mathrm{Fe}$ & $5.0 \pm 0.9$ & $6.1 \pm 1.0$ & $6.6 \pm 1.0$ & $5.7 \pm 0.4$ \\
$\mathrm{Cr}$ & $4.4 \pm 0.6$ & $4.9 \pm 0.7$ & $2.5 \pm 0.5$ & $6.4 \pm 0.5$ \\
\hline Pulse (\%) & 15 & 25 & 15 & 20 \\
Temp. (K) & 80 & 80 & 90 & 80 \\
Contrast & dark & dark & bright & bright \\
\hline
\end{tabular}

\subsection{Field evaporation of carbon}

In most cases the number of collected ions from one grain boundary is very limited because the analysis direction is generally not parallel to the interface plane. Therefore, any statistical analysis of the ions originating from a grain boundary is normally not applicable. However, in the present investigation about 10.000 ions from one grain boundary in Alloy A, which had been heat treated at $600^{\circ} \mathrm{C}$ for one hour, could be detected. This number of ions is sufficiently large to justify the use of statistical methods to investigate clustering of elements.

The concentration of carbon at the grain boundary was 1.5 at. $\%$ and about $30 \%$ of the carbon was detected as complex ions $\left(\mathrm{C}_{2}{ }^{+}\right.$and $\left.\mathrm{C}_{3}{ }^{2+}\right)$. This large fraction of complexes is comparable with the amount of complex ions detected when analysing carbides. It is well known that in atom probe analysis of carbides, a large fraction of the carbon atoms are field evaporated as complex ions, e.g. $\mathrm{C}_{2}{ }^{+}, \mathrm{C}_{3}{ }^{2+}$ and $\mathrm{C}_{3}+[20,21]$. The interpretation of this phenomenon has been discussed in several papers, especially in investigations of martensite $[22,23]$. It is still not known whether the carbon complex ions are clustered in the material prior to analysis or form on the surface of the specimen under the influence of the applied field.

To further evaluate the results the concentration of the nearest and next nearest neighbours to carbon in the ion chain was calculated and compared with the grain boundary composition. In most cases only one ion from one pulse was detected. When more than one ion originated from the same pulse, the mutual order of these was randomized, to avoid biasing effects. If the timing channels were filled, these ions were omitted. The results, presented in table 3 , show a tendency for chromium ions to appear next to carbon. Even though the value of a nearest neighbour test should not be overestimated [24], since the distance between two ions that were next to each other can be as large as the probe hole diameter (about $3 \mathrm{~nm}$ ), it can be concluded from table 3 that carbon and chromium often field evaporate closely in time and space.

Table 3. Concentration (in at.\%) of nearest and next nearest neighbours in the atom probe ion chain, with respect to carbon. It is evident that field evaporation of carbon and chromium is correlated.

\begin{tabular}{cccc}
\hline Element & Grain boundary & Nearest neighbour & Next nearest neighbour \\
\hline $\mathrm{C}$ & $1.5 \pm 0.2$ & - & - \\
$\mathrm{Cr}$ & $19.6 \pm 0.5$ & $30.4 \pm 3.4$ & $25.4 \pm 3.0$ \\
$\mathrm{Fe}$ & $10.5 \pm 0.4$ & $8.9 \pm 1.9$ & $9.0 \pm 1.8$ \\
$\mathrm{Ni}$ & $68.0 \pm 0.9$ & $60.7 \pm 4.9$ & $65.6 \pm 4.8$ \\
\hline
\end{tabular}

The presence of complex carbon ions together with the interdependence of carbon and chromium field evaporation observed at the grain boundary indicate the existence of small nucleus of chromium carbides. Even if TEM analysis (thin foils and extraction replicas) of the material did not reveal any signs of intergranular precipitation, TTT-diagrams show that $\mathrm{Cr}_{7} \mathrm{C}_{3}$ will form in the material after heat treatment for sufficiently long time at $600^{\circ} \mathrm{C} \mathrm{[3],} \mathrm{which} \mathrm{supports} \mathrm{our} \mathrm{statement.} \mathrm{Also,} \mathrm{in} \mathrm{commercial} \mathrm{materials} \mathrm{with}$ higher carbon concentration ( 0.2 at.\%) precipitation of intergranular $\mathrm{Cr}_{7} \mathrm{C}_{3}$ has been observed after the same heat treatment [25]. 


\section{CONCLUSIONS}

(i) Atom probe analysis of $\mathrm{Ni}_{23} \mathrm{~B}_{6}$ is sensitive to preferential field evaporation of nickel. At $80 \mathrm{~K}$ a pulse fraction of $25 \%$ gives the expected composition, whereas at $40 \mathrm{~K}$ a pulse fraction of $20 \%$ is sufficient.

(ii) Intergranular nickel borides can appear bright or dark in FIM images, with respect to the matrix.

(iii) Nucleation of intergranular chromium carbides occurs in less than one hour at $600^{\circ} \mathrm{C}$.

\section{Acknowledgement}

This work was supported by Swedish Research Council for Engineering Science (TFR).

\section{References}

[1] Was G.S., Corrosion 46 (1990) 319-330.

[2] Bruemmer S.M. and Was G.S., J. Nucl. Mat. 216 (1994) 348-363.

[3] Scarberry R.C., Pearman S.C. and Crum J.R., Corrosion 32 (1976) 401-406.

[4] Kruger R.M. and Was G.S., Metall. Trans. A 19 (1988) 2555-2566.

[5] Thuvander M. and Stiller K., Appl. Surf. Sci. $87 / 88$ (1995) 251-256.

[6] Thuvander M., Stiller K., Blavette D. and Menand A., Appl. Surf. Sci. 94/95 (1996) 343-350.

[7] Stiller K., Nilsson J.-O. and Norring K., Metall. Trans. A 26 (1995) 1-15.

[8] Stiller K., Surf. Sci. 266 (1992) 402-408.

[9] Andrén H.-O. and Nordén H., Scand. J. Metallurgy 8 (1979) 147-152.

[10] Andrén H.-O., J. Phys. (Paris) 47-C7 (1986) 483-488.

[11] Rolander U. and Andrén H.-O., Surf. Sci. 246 (1991) 390-395.

[12] Henjered A. and Nordén H., J. Phys. E 16 (1983) 617.

[13] Alvensleben L.v., J. Phys. (Paris) 49-C6 (1988) 335-340.

[14] Miller M.K. and Smith G.D.W., Atom Probe Microanalysis (Mater. Res. Soc., Pittsburgh, PA, 1989) pp. 61-95.

[15] Jayaram R. and Miller M.K., Surf. Sci. 266 (1992) 310-315.

[16] Yamamoto M., Sugiyama A., Matsushima H., Uemori R. and Morikawa H., Surf. Sci. 266 (1992)

322-327.

[17] Miller M.K, and Jayaram R., Surf. Sci. 266 (1992) 458-462.

[18] Smithells C.J., Metals Reference Book, 5th ed. (Butterworths, London, 1976) p. 11-101.

[19] Collins H.E., Trans. ASM 62 (1969) 82-104.

[20] Rolander U. and Andrén H.-O., J. Phys. (Paris) 50-C8 (1989) 371-376.

[21] Sha W., Chang L., Smith G.D.W., Cheng L. and Mittermeijer E.J., Surf. Sci. 266 (1992) 416-423.

[22] Miller M.K., Beaven P.A., Brenner S.S. and Smith G.D.W., Metall. Trans. A 14 (1983) 10211024.

[23] Olsen G.B. and Cohen M., Metall. Trans. A 14 (1983) 1057-1065.

[24] Miller M.K., Beaven P.A. and Smith G.D.W., Metall. Trans. A 12 (1981) 1197-1204.

[25] Airey G.P., Metallography 13 (1980) 21-41. 